\title{
Dynamic Assessment of Water resources Security in Karst Area Based on PESBR Model
}

\author{
Ling-zhi Deng ${ }^{1}$, Zhen-hua Yang ${ }^{1}$, Wei-ci Su ${ }^{2 . a . *}$ \\ ${ }^{1}$ School of geography and environment; Guizhou Normal University, Guiyang 550001, China \\ ${ }^{2}$ Institute of karst Guizhou Normal University, Guiyang 550001, China \\ Institute of mountain resources, Guizhou Academy of Sciences, Guiyang, 550001, China; School of \\ Geography and Tourism Chongqing Normal University, Chongqing, 400047, China \\ aemail: suweici@sina.com \\ ${ }^{*}$ Corresponding author
}

Keywords: PESBR, Karst, Water resources security, Assessment.

\begin{abstract}
It's urgently needed to solve the "Engineering water shortage" problem cause of serious leakage of surface water, poor water resources availability and difficult water resources utilization in Karst area in Southwest China. To reasonable evaluate water resources security situation in karst area, this paper based on the conceptual model of Water demand pressure - Engineering water shortage - Carrying state - Ecological basis - Human response (PESBR) to build evaluation index system of water resources safety which covered condition of water conservancy engineering, then adopted the coupling model of Set pair analysis and Markov chain (SPA-MC) to dynamic evaluated water resources security situation in Guiyang city during 2002 2014. Research results shown that: the water resources security of Guiyang City in 2008, 2012, 2014 are belongs to "safe" level, the rest years are "general safe" level. And it is transiting from "general safe" to "safe" on the whole. The average safe grade contact f2 and f3 are 0.13 and 0.20 , confidence level H2 and H3 are between 0.5 degrees. The prediction result of water resources security in Guiyang city during 2015 to 2050 shown that the future water resources security will remain "general safe" level for long time.
\end{abstract}

\section{Introduction}

Karst Landform is "Binary-3D”space structure system which composed of a double water medium, with special topography-drainage structure and hydrologic dynamic process, surface water storage ability is restricted, furthermore water resources can be used or convenient to be utilized are relatively limited[1-3]. At the same time, the city population continues growing, industrial and agricultural are developing rapidly, a large number of production and living sewage emissions, which make seriously damage to the water environment quality, exacerbate regional water difficulty which lead to water resources become a important restricting factor of social and economic development in many karst area. Water resources security issue has became a hot research field of karst[4-6]. Therefore, constructing a scientific evaluation index system, using suitable model to carry out the research on water resource security evaluation in karst area is particularly important to ensure safety of city water resources and draft water resources safety utilization planning in karst area.

At present, the research productions of water resources safety assessment is mainly concentrated in the evaluation index system construction, evaluation model design and selection, such as constructed index system from view of DPSIRM, DPSIR, RSR concept model[7-9], selected the WEAP mode [10], CN-AM model[11], projection pursuit model [12], system dynamics [13], SPA 
model [14], support vector machine[15], cluster analysis method [16] and other models or methods to evaluate water resources safety . these models also has made some progress on karst water resource security evaluation, such as ZHANG (ZHANG F T, et al;) constructed coupling model with entropy weight and set pair model of water resources safety evaluation in Guizhou Province based on analyzed the binary characteristics of water resources in the surface karst zone [17]; ZOU(ZOU S Z, et al;)putted forward that safety assessment of water resources in karst area of southwest China should include water evaluation Quality and amount, utilization of water resources and water disaster prevention[18]; DUAN(DUAN Q C, et al;)combined Karst topography, water cycle distribution difference, population economic distribution, etc. in Yunnan province to analyze the influencing factors of water resources security[19]; it's obviously that a majority of previous model and index system of traditional water resources safety assessment are applied directly in karst area, and still exist the following problems: (1) the selected index system does not reflect the characteristics of water engineering in karst area, also cannot highlighted the characteristics of karst water resources, the evaluation results objectivity is questionable. (2) Because of the evaluation model limits evaluation process which take more attention over water resources security status while ignoring the dynamic evolution process of influencing factors, and linear trend data analysis over the years cannot highlight the security of water resources, forecast research on water resources security is relatively weak.

Added water engineering characteristics (Engineering water shortage) and ecological conditions (Basal condition) into PSR model to design the improved PESBR model that based on PSR concept, which will contribute to the scientific construction of water resources security evaluation system in Karst area. The SPA-MC coupled model utilizes connection degree of set pair to measure certainty and uncertainty in water resources security system, then, use antithetical couplet transformation rules to predict the change trend of state sequence, so as to realize the dynamic evaluation and prediction of water resources security. Among them, the fuzzy set pair analysis (SPA) is used to investigate the uncertainty and certainty of the water resources security system as a system [20-21]. Markov chain (MC) mainly through stable transition probability of random water resources security state to predict the change trend, which has high short-term prediction accuracy for the safety level of water resources [22].

Based on above-mentioned reasons, This paper according to convert law of atmospheric water--surface water--groundwater, significant Engineering water shortage and low utilization efficiency of water resources in agriculture and Industry in karst area Constructed index system based on PESBR (press-Engineering-stage-basis-response) conceptual model, after that. Dynamically evaluated water resources safety in Guiyang city during 2002-2014 with SPA-MC model, and predicted the change trend in 2015-2050, which provided scientific support and decision-making basis for water resources sustainable utilization and regional economic development in Karst area.

\section{Safety Assessment Model of Water Resources}

The surface water storage capacity is weak where karst intensely developed, which as a result of fragile ecological environment and low surface runoff coefficient. In addition, complex engineering geological conditions, difficult to construct water conservancy facilities, serious engineering water shortage, which lead to critical water resources security problems in karst area[23-25]. The crux of water resources security is whether water resources could guarantee to meet the demand of sustainable development in karst area, and the coordination of water circulation system, which includes two aspects: first, in the different rainfall runoff and water supply engineering conditions, 
the amount of available water resources (including natural and artificial regulation of occurrence) to meet needs of the regional social and economic development; second, the artificial intervention in social economic activities on water resources and water environment should be in the water ecological carrying capacity range. In this paper, based on the connotation of water resources security, the characteristics of water resources supply and demand in karst area, the PESBR concept model of water resources safety was designed (Fig. 1)

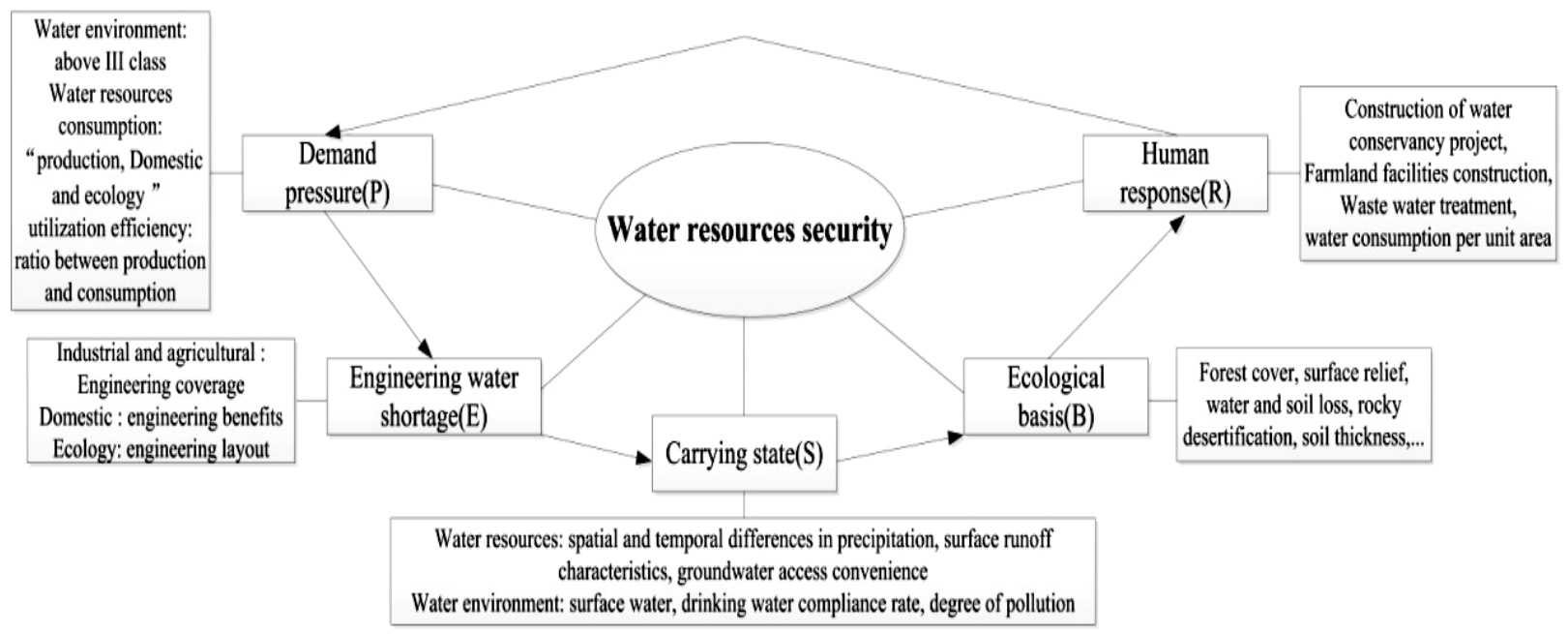

Fig. 1 PESBR conceptual framework model of water resources safety

\section{Index System Construction}

According to the PESBR concept model, established water resources safety evaluation index system which covering 5 parts of Water demand pressure $(\mathrm{P})$, Engineering water shortage $(\mathrm{E})$, Carrying state(S), Ecological basis(B) and Human response(R), including 5 evaluation criteria and 27 evaluation indexes . Moreover the indexes are divided into positive and negative indicators (Table 1). 
Table 1 Evaluation index system of water resources security in Karst Area

\begin{tabular}{|c|c|c|c|c|}
\hline $\begin{array}{l}\text { Target } \\
\text { layer }\end{array}$ & $\begin{array}{l}\text { Criterion } \\
\text { layer }\end{array}$ & & Index layer / (unit) & weight \\
\hline \multirow{8}{*}{ Safety } & \multirow{6}{*}{$\begin{array}{l}\text { Demand } \\
\text { pressure(P) }\end{array}$} & $X_{1^{-}}$ & Population density / $\left(\mathrm{p} / \mathrm{km}^{2}\right)$ & 0.039 \\
\hline & & $X_{2^{-}}$ & Urbanization level / (\%) & 0.045 \\
\hline & & $X_{3}^{+}$ & Per capita water resources $\left(\mathrm{m}^{3} / \mathrm{a}\right)$ & 0.052 \\
\hline & & $X_{4^{-}}$ & Proportion of domestic water consumption / (\%) & 0.050 \\
\hline & & $X_{5}+$ & Ecological water demand / (\%) & 0.034 \\
\hline & & $X_{6^{-}}$ & $\begin{array}{l}10000 \text { yuan GDP water consumption / }\left(\mathrm{m}^{3} / 10^{4}\right. \\
\text { yuan })\end{array}$ & 0.056 \\
\hline & Engineering & $X_{7^{-}}$ & $\begin{array}{l}\text { Proportion of Upgrade and draw engineering } \\
\text { water supply / (\%) }\end{array}$ & 0.042 \\
\hline & $\begin{array}{l}\text { water } \\
\text { shortage(E) }\end{array}$ & $X_{8}+$ & $\begin{array}{l}\text { Large and medium size reservoir storage rate / } \\
(\%)\end{array}$ & 0.051 \\
\hline \multirow{5}{*}{ assessment } & & $X_{9}+$ & Effective irrigation area ratio / (\%) & 0.034 \\
\hline & & $X_{10^{-}}$ & Spatial heterogeneity of precipitation / (\%) & 0.026 \\
\hline & & $X_{11^{-}}$ & Seasonal variability of precipitation / (\%) & 0.031 \\
\hline & & $X_{12}+$ & Water yield modulus / $\left(\mathrm{m}^{3} / \mathrm{km}^{2}\right)$ & 0.022 \\
\hline & & $X_{13}+$ & Surface runoff density $\left(\mathrm{km} / \mathrm{km}^{2}\right)$ & 0.020 \\
\hline \multirow{8}{*}{ of } & \multirow{5}{*}{$\begin{array}{l}\text { Carrying } \\
\text { state(S) }\end{array}$} & $X_{14^{+}}$ & Runoff coefficient & 0.033 \\
\hline & & $X_{15^{+}}$ & Entry and exit water Surplus $\left(10^{8} \mathrm{~m}^{3}\right)$ & 0.027 \\
\hline & & $X_{16^{-}}$ & Groundwater specific gravity / (\%) & 0.024 \\
\hline & & $X_{17}+$ & Drinking water quality compliance rate / (\%) & 0.029 \\
\hline & & $X_{18}+$ & Urban surface water quality status / (\%) & 0.036 \\
\hline & \multirow{3}{*}{$\begin{array}{l}\text { Ecological } \\
\text { basis(B) }\end{array}$} & $X_{19}+$ & Forest coverage rate/ $(\%)$ & 0.032 \\
\hline & & $X_{20^{-}}$ & Karst rocky desertification rate/ (\%) & 0.025 \\
\hline & & $X_{21^{-}}$ & Sediment transport modulus / $\left(\mathrm{t} / \mathrm{km}^{2} . \mathrm{a}\right)$ & 0.038 \\
\hline \multirow{4}{*}{ water } & \multirow{6}{*}{$\begin{array}{l}\text { Human } \\
\text { response(R) }\end{array}$} & $X_{22}+$ & Dangerous reservoir treatment rate / $(\%)$ & 0.032 \\
\hline & & $X_{23}+$ & $\begin{array}{l}\text { Ten thousand yuan GDP pollutant emission } \\
\text { reduction rate / }(\%)\end{array}$ & 0.036 \\
\hline & & $X_{24}^{+}$ & Standard rate of industrial waste water / (\%) & 0.040 \\
\hline & & $X_{25^{+}}$ & $\begin{array}{l}\text { Fertilizer use efficiency of cultivated land / } \\
(\mathrm{kg} / \mathrm{ha} . \mathrm{a})\end{array}$ & 0.048 \\
\hline & & $X_{26}+$ & Domestic sewage treatment rate / $(\%)$ & 0.044 \\
\hline resources & & $X_{27^{+}}$ & $\begin{array}{l}\text { Water resources development and utilization / } \\
(\%)\end{array}$ & 0.052 \\
\hline
\end{tabular}

Note: the "+ / -"of $X_{i}+/$ - $(i=1,2, \ldots, 27)$ behalf of the index positive / negative attribute.

\section{Index Weighting}

On the basis of constructed evaluation index system, combined AHP method and variation coefficient method[26]for determinate index weight, so as to realize the combination of subjective preference and objective correlation[27], and its value is shown in Table 1. 


\section{Index Classification}

In consideration of the ecosystem vulnerability and hydrological cycle regularity in karst area, and the related literature[7-9,13-16] about the existing water resources safety standards, and combined with the standards and planning on water resource safety which promulgated by domestic and foreign government, and the experts opinions to classify water resources security into 5 levels that are safe, Relatively safe, General safe, Relatively unsafe and unsafe and determined the evaluation indexes classification standard (Table 2)

Table 2 Classification criteria of water resources safety evaluation index

\begin{tabular}{|c|c|c|c|c|c|c|}
\hline $\begin{array}{c}\text { Criterion } \\
\text { layer }\end{array}$ & $\begin{array}{c}\text { Evaluation } \\
\text { index }\end{array}$ & Safe & Relatively safe & General safe & $\begin{array}{c}\text { Relatively } \\
\text { unsafe }\end{array}$ & Unsafe \\
\hline \multirow{6}{*}{$\mathrm{P}$} & $X_{1^{-}}$ & {$[0,100)$} & {$[100,200)$} & {$[200,300)$} & {$[300,400)$} & $\geq 400$ \\
\hline & $X_{2^{-}}$ & $(85,100]$ & $(70,85]$ & $(50,70]$ & $(30,50]$ & {$[0,30]$} \\
\hline & $X_{3}+$ & $>3000$ & $(2000,3000]$ & $(1000,2000]$ & $(500,1000]$ & $\leq 500$ \\
\hline & $X_{4^{-}}$ & {$[0,5)$} & {$[5,10)$} & {$[10,15)$} & {$[15,20)$} & $\geq 20$ \\
\hline & $X_{5}+$ & $>45$ & $(40,45]$ & $(35,40]$ & $(30,35]$ & $\leq 30$ \\
\hline & $X_{6^{-}}$ & {$[0,300)$} & {$[300,600)$} & {$[600,1000)$} & {$[1000,1500)$} & $\geq 1500$ \\
\hline \multirow{3}{*}{ E } & $X_{7^{-}}$ & {$[0,10)$} & {$[10,20)$} & {$[20,30)$} & {$[30,40)$} & $\geq 40$ \\
\hline & $X_{8}+$ & $(85,100]$ & $(70,85]$ & $(65,70]$ & $(50,65]$ & $\leq 50$ \\
\hline & $X_{9}+$ & $(80,100]$ & $(60,80]$ & $(40,60]$ & $(20,40]$ & $\leq 20$ \\
\hline \multirow{9}{*}{ S } & $X_{10^{-}}$ & {$[0,0.2)$} & {$[0.2,0.4)$} & {$[0.4,0.6)$} & {$[0.6,0.8)$} & $\geq 0.8$ \\
\hline & $X_{11^{-}}$ & {$[0,0.3)$} & {$[0.3,0.6)$} & {$[0.6,0.9)$} & {$[0.9,1.2)$} & $\geq 1.2$ \\
\hline & $X_{12}+$ & $\geq 20$ & {$[10,20)$} & {$[5,10)$} & {$[1,5)$} & {$[0,1)$} \\
\hline & $X_{13}+$ & $\geq 10$ & {$[7,10)$} & {$[5,7)$} & {$[3,5)$} & {$[0,3)$} \\
\hline & $X_{14^{+}}$ & {$[0.8,1]$} & {$[0.6,0.8)$} & {$[0.4,0.6)$} & {$[0.2,0.4)$} & {$[0,0.2)$} \\
\hline & $X_{15^{+}}$ & $\geq 60$ & {$[50,60)$} & {$[40,50)$} & {$[30,40)$} & $<30$ \\
\hline & $X_{16^{-}}$ & {$[0,0.1)$} & {$[0.1,0.2)$} & {$[0.2,0.3)$} & {$[0.3,0.4)$} & $\geq 0.4$ \\
\hline & $X_{17}+$ & $(95,100]$ & $(90,95]$ & $(85,90]$ & $(80,85]$ & $\leq 80$ \\
\hline & $X_{18}+$ & $(95,100]$ & $(85,95]$ & $(80,85]$ & $(70,80]$ & $\leq 70$ \\
\hline \multirow{3}{*}{ C } & $X_{19^{+}}$ & $\geq 40$ & {$[35,40)$} & {$[30,35)$} & {$[20,30)$} & $<20$ \\
\hline & $X_{20^{-}}$ & $\geq 20$ & {$[15,20)$} & {$[10,15)$} & {$[5,10)$} & $<5$ \\
\hline & $X_{21^{-}}$ & $<200$ & {$[200,1000)$} & {$[1000,2500)$} & {$[2500,5000)$} & $\geq 5000$ \\
\hline \multirow{6}{*}{$\mathrm{R}$} & $X_{22}+$ & $(90,100]$ & $(80,90]$ & $(80,70]$ & $(60,70]$ & $\leq 60$ \\
\hline & $X_{23}+$ & $(90,100]$ & $(80,90]$ & $(80,70]$ & $(60,70]$ & $\leq 60$ \\
\hline & $X_{24^{+}}$ & {$[0,125)$} & {$[125,225)$} & {$[225,350)$} & {$[350,475)$} & $\geq 475$ \\
\hline & $X_{25}+$ & $(85,100]$ & $(75,85]$ & $(65,75]$ & $(55,65]$ & $\leq 55$ \\
\hline & $X_{26^{+}}$ & $>20$ & $(10,20]$ & $(0,10]$ & $(-10,0]$ & $\leq-10$ \\
\hline & $X_{27^{+}}$ & {$[0,15)$} & {$[15,30)$} & {$[30,40)$} & {$[40,50)$} & $\geq 50$ \\
\hline
\end{tabular}




\section{Evaluation Model}

\section{Fuzzy Set Pair Analysis}

SPA theory was used as a set of evaluation index system and security level as a set pair, according to the index system $X_{i}$ the evaluation grade $B_{k}$ structure set to $H\left(x_{i}, B_{k}\right)(k=1,2,3,4,5 ; i=1,2,3, \ldots s, n)$, the multiple contact degree is $\mathrm{k}=5$ [28]. and

$$
\begin{aligned}
& \eta(X, B)=w \eta\left(x_{i}, B\right)=\sum_{l=1}^{m} w_{l} a_{l}+\sum_{l=1}^{m} w_{l} b_{l, 1} i_{1}+\sum_{l=1}^{m} w_{l} b_{l, 2} i_{2}+\sum_{l=1}^{m} w_{l} b_{l, 2} i_{3}+\sum_{l=1}^{m} c_{l} j \\
& f_{1}=\sum_{l=1}^{m} w_{l} a_{l} f_{2}=\sum_{l=1}^{m} w_{l} b_{l} i_{1} f_{3}=\sum_{l=1}^{m} w_{l} b_{l} i_{2} \quad f_{4}=\sum_{l=1}^{m} w_{l} b_{l} i_{3} f_{5}=\sum_{l=1}^{m} c_{i} J \\
& \eta(X, B)=f_{1}+f_{2} I_{1}+f_{3} I_{2}+f_{4} I_{3}+f_{5} J
\end{aligned}
$$

Because the value of $I_{1}, I_{2}, I_{3}$ and $J$ in the operation process only plays the role (each values are 1 ), $\mathrm{f} 1, \mathrm{f} 2+\mathrm{f} 3+\mathrm{f} 4, \mathrm{f} 5$ representative set pair. the set of $B_{k}$ the same degree, the degree of opposition and difference. At the same time, according to the index (the more optimal) and negative indexes (smaller type) respectively according to the following formula (3) and (4)calculation: For the negative indicators, the relationship between the index value $X_{i}$ and the evaluation criteria of the index level ${ }^{\eta\left(X_{i}, B_{k}\right)}$ is as follows [28]:

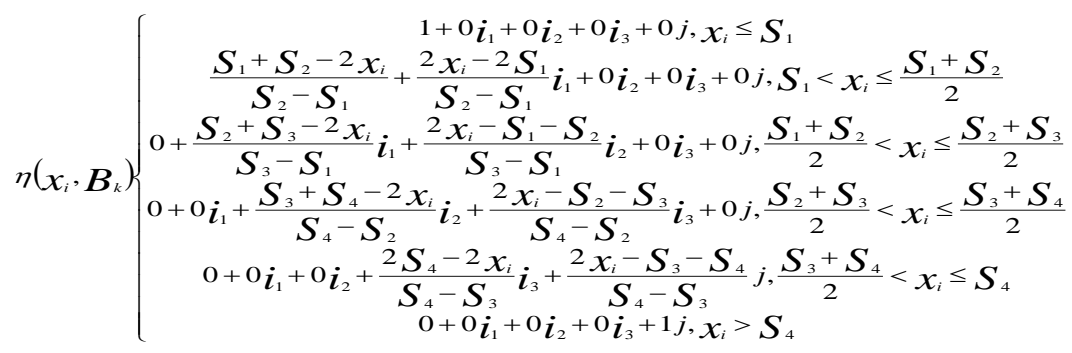

For the positive index, the relationship between the index $X_{i}$ and the evaluation criteria of $k$ the index grade $\eta\left(x_{i}, B_{k}\right)$ is as follows:

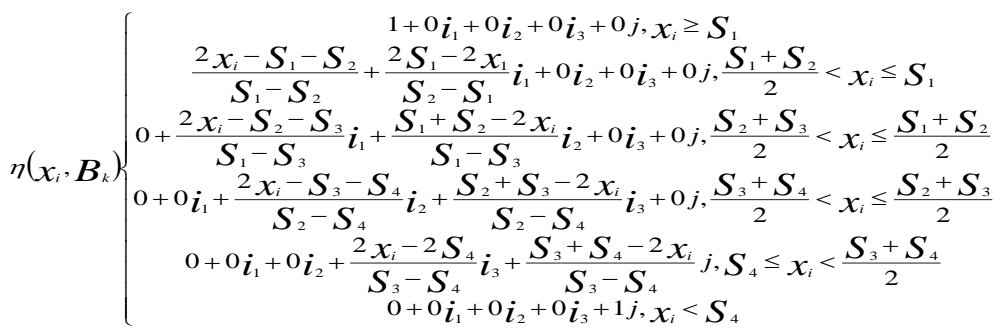


In addition, this paper used confidence criterion below to determine the level of the sample.

$$
h_{k}=\left(f_{1}+f_{2}+\cdots+f_{k}\right)>\lambda, k=1,2,3,4,5
$$

In the formula(5), $\lambda$ for the confidence, its value is generally recommended in the range of $[0.5,0.7]$.

\section{Markov Chain}

Let $\mathrm{P}$ be a probability space, $\{C(n), n \geq 0\}_{\text {is }}$ the definition of integer random sequence in probability space.

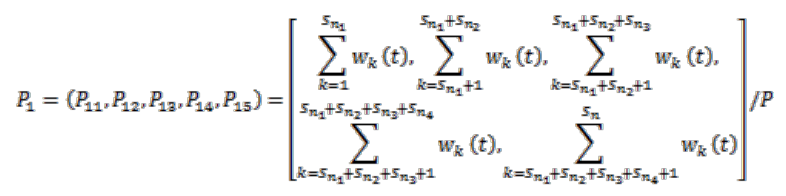

Similarly, the $P_{2}, P_{3}, P_{4}, P_{5}$ the corresponding transition probability vector, and then the evaluation index system in the $\left[t_{m}, t_{m}+\Delta t\right]$ trans-probability matrix is:

$$
P_{n}=\left[\begin{array}{ccc}
P_{11} & \cdots & P_{15} \\
\vdots & \ddots & \vdots \\
P_{51} & \cdots & P_{55}
\end{array}\right]
$$

The security level and the state of transition probability matrix determined by the above SPA, the establishment of water resources security evaluation model, using the principle of membership is $\left[t_{m}, t_{m}+\Delta t\right]$ period, the security assessment of water resources value is:

$$
\mu_{A-B}(t+n \Delta f)=\left[d(t), e(t), f(t), g(t), h(t)_{n}\right]^{* P^{n} i *}\left(1, i_{l}, i_{2}, i_{3} j^{T}\right.
$$

\section{Case Analysis}

\section{Overview of Study Area}

Guiyang city is located in the Yunnan Guizhou Plateau to the east slope, China eastern hills to the transition zone of the western plateau. Terrain, topography, the trend of things to extend, the north and South high, middle low, large surface relief. Karst landforms are widely developed, which not only have high mountain and hills, but also basin and valley, platform, and the elevation is between 872-1659m. Three Guiyang County, under the jurisdiction of the six District of a city, with a total area of $8034 \mathrm{~km} 2$. Guiyang City perennial controlled by westerly belt, belongs to the subtropical humid and mild climate, which has the obvious characteristics of the plateau monsoon climate, the annual average temperature is $15.3^{\circ} \mathrm{C}$, the annual average relative humidity is $78 \%$, the average annual precipitation is $1129.5 \mathrm{~mm}$. The annual runoff of $45.28 \times 108 \mathrm{~m} 3$ and the runoff density is $12.4 \mathrm{~km} / \mathrm{km} 2$. 


\section{Data Sources}

The research data mainly comes from the "Guiyang water resources bulletin" (2002-2014), "Guiyang environmental statement" (2002-2014) and the "Guiyang Statistical Yearbook", "Guiyang Yearbook", "national economic and social development statistical bulletin" (2002-2014). Some indicators involving other data sources are described as follows: the seasonal precipitation variability calculated by Guiyang national meteorological stations data; surface runoff density (X13) extracted from Guiyang city drainage map (1:50000); karst rocky desertification rate (X20) were used to provide land sector data, missing values obtained by the year the annual rocky desertification area; in addition, the standard rate of industrial wastewater (X24) and sewage treatment rate (X26) in recent years the data according to the average growth rate of the previous year interpolation.

\section{Evaluation Results and Analysis}

\section{Water Resources Safety Assessment}

According to the type (3-4) structure of water resources security evaluation factors and evaluation grade set pair analysis, and contact analysis of identity $f_{1}$ and difference $f_{2-4}$, opposition $f_{5}$, obtained water resources safety evaluation index of connection degree during 2002-2014 in Guiyang city, then. Combining with connection degree and the weight of each index so as to gain the safety level of water resources and evaluation level of connection degree, take $\lambda=0.5$ as a dividing line, $H_{3}=f_{1}+f_{2}+f_{3}=0.55>\lambda$ is the confidence criterion [30] can determine the security of water resources in Guiyang city 2002, similarly, also can calculate the water resources safety during 2003-2014 in Guiyang city (Table 3).

Table 3 Relationship of water resources safety grade in Guiyang city 2002-2014

\begin{tabular}{ccccccc}
\hline Year & $f_{1}$ & $f_{2}$ & $f_{3}$ & $f_{4}$ & $f_{5}$ & Evaluation level \\
\hline 2002 & 0.299 & 0.084 & 0.168 & 0.149 & 0.298 & General safe \\
2003 & 0.229 & 0.087 & 0.219 & 0.207 & 0.255 & General safe \\
2004 & 0.188 & 0.116 & 0.247 & 0.191 & 0.255 & General safe \\
2005 & 0.219 & 0.146 & 0.248 & 0.112 & 0.272 & General safe \\
2006 & 0.229 & 0.116 & 0.262 & 0.162 & 0.227 & General safe \\
2007 & 0.249 & 0.147 & 0.238 & 0.138 & 0.225 & General safe \\
2008 & 0.310 & 0.192 & 0.140 & 0.128 & 0.226 & Relatively safe \\
2009 & 0.252 & 0.174 & 0.195 & 0.118 & 0.258 & General safe \\
2010 & 0.289 & 0.102 & 0.236 & 0.159 & 0.211 & General safe \\
2011 & 0.334 & 0.094 & 0.184 & 0.096 & 0.289 & General safe \\
2012 & 0.476 & 0.062 & 0.170 & 0.089 & 0.200 & Relatively safe \\
2013 & 0.262 & 0.181 & 0.205 & 0.116 & 0.232 & General safe \\
2014 & 0.354 & 0.183 & 0.133 & 0.126 & 0.200 & Relatively safe \\
\hline
\end{tabular}

Table 3 shows the level of water resources security in Guiyang city during 2002-2014 are relatively safe except for 2005, 2012 and 2014, the rest year are the general level of security, the security level of water resources changes over the years is small, and showed a fluctuant rising trend, the cumulative contact ratio of $\mathrm{H} 3$ and the degree of confidence distance is gradually small trend. This shows that Guiyang city has a larger increase in the ability of water supply and water use efficiency, ecological civilization in the process of city construction, water conservancy facilities continue to improve, optimize the industrial structure, the ecological environment tends to be benign outcome. 


\section{Dynamic Prediction of Water Resources Security}

Inter-annual variation of uncertainty and social and economic factors of the system of utilization of water resources, leading to higher coefficient of variation over the index of water resources safety assessment $(\mathrm{Cv}=0.235)$, which belongs to the discrete time series with Markov process. Based on the correlation degree of each index, the paper uses the Markov chain (MC) to forecast the trend of water resources security in Guiyang city during 2015-2020. The evaluation index of water resources security in Guiyang city was combined with the weight of 2015-2020, and 2002-2003, 2003-2004,..., 2013-2014 were calculated, in each period, the formula (7) obtained in the steady state of water resources in 2002-2014 security trans-probability matrix values (Fig. 2)

$$
P_{\Delta \mathrm{t}}=\left[\begin{array}{ccccc}
0.886 & 0.082 & 0.019 & 0.014 & 0 \\
0.192 & 0.638 & 0.161 & 0 & 0.009 \\
0.080 & 0.143 & 0.620 & 0.117 & 0.040 \\
0.030 & 0 & 0.252 & 0.664 & 0.054 \\
0.009 & 0.009 & 0.023 & 0.059 & 0.900
\end{array}\right]
$$

Fig. 2 Transition probability matrix of water resources safety

Because the $P_{\Delta \mathrm{t}}$ satisfies the C-K equation, namely $\Delta \mathrm{t}$ after multiple cycles, the $\mathrm{P}_{-} \mathrm{t}$ tends to be stable. According to the ergodicity of the Markov process into equation (8) predicted Guiyang city water resources safety degree contact can be obtained in the future value (Table 4) and the Guiyang city water resources security steady connection degree is $\eta(X, B)=[0.2006,0.2001,0.1999,0.1998$, 0.1995], which in a state of security, with the overall the situation of water resources security system and over the years. As can be seen from table 4, 2015-2050 Guiyang water resources security level will be long in a more secure state, that is from general safe to relatively safe Transition trend. the overall level of f1, f2, f3 are increase year by year, which f1 from 0.435 in 2015 rise to 0.365 in 2050, gradually to the confidence that the future will be close to 0.5 , the single index of water resources security more to the security level changes. The grade of $\mathrm{f} 4 \mathrm{f} 5 \mathrm{will}$ continue to decline, especially the level of 5 decreased by 0.056 , the rate of decline of $28.86 \%$, showed that under the influence of human factors, the water resources security single index grade increased significantly.

Table 4 Forecast value of water resources security in Guiyang city during 2015-2030 (MC)

\begin{tabular}{ccccccl}
\hline Year & $f_{1}$ & $f_{2}$ & $f_{3}$ & $f_{4}$ & $f_{5}$ & Evaluation level \\
\hline 2015 & 0.365 & 0.167 & 0.155 & 0.116 & 0.194 & Relatively safe \\
2016 & 0.373 & 0.160 & 0.164 & 0.112 & 0.188 & Relatively safe \\
2017 & 0.379 & 0.158 & 0.167 & 0.110 & 0.184 & Relatively safe \\
2018 & 0.385 & 0.157 & 0.168 & 0.108 & 0.179 & Relatively safe \\
2019 & 0.389 & 0.158 & 0.168 & 0.108 & 0.175 & Relatively safe \\
2020 & 0.393 & 0.158 & 0.168 & 0.107 & 0.172 & Relatively safe \\
2030 & 0.419 & 0.164 & 0.168 & 0.103 & 0.150 & Relatively safe \\
2050 & 0.435 & 0.168 & 0.168 & 0.101 & 0.138 & Relatively safe \\
\hline
\end{tabular}

\section{Driving factor analysis}

According to the weighted grade of each evaluation criterion, the main driving factors of water resources security level in Guiyang City, 2002-2014, were identified. According to Table 3 and Fig. 
5 shows that the 2002-2014 in Guiyang city water resources safety is mainly composed of P, E, S, B, $\mathrm{R}$ and other factors on $\mathrm{f} 1, \mathrm{f} 2$, $\mathrm{f} 3$ weighted connection degree level decision of high grade with higher degree, water resources security level is higher, and vice versa. At the same time, the elements which affect unsafe and relatively unsafe are less and less, Conversely the elements which affect safe and relatively safe are more and more in Guiyang city since 2002, especially P, S, R elements are gradually changing from unsafe and relatively unsafe to safe and relatively safe(Fig. 3).
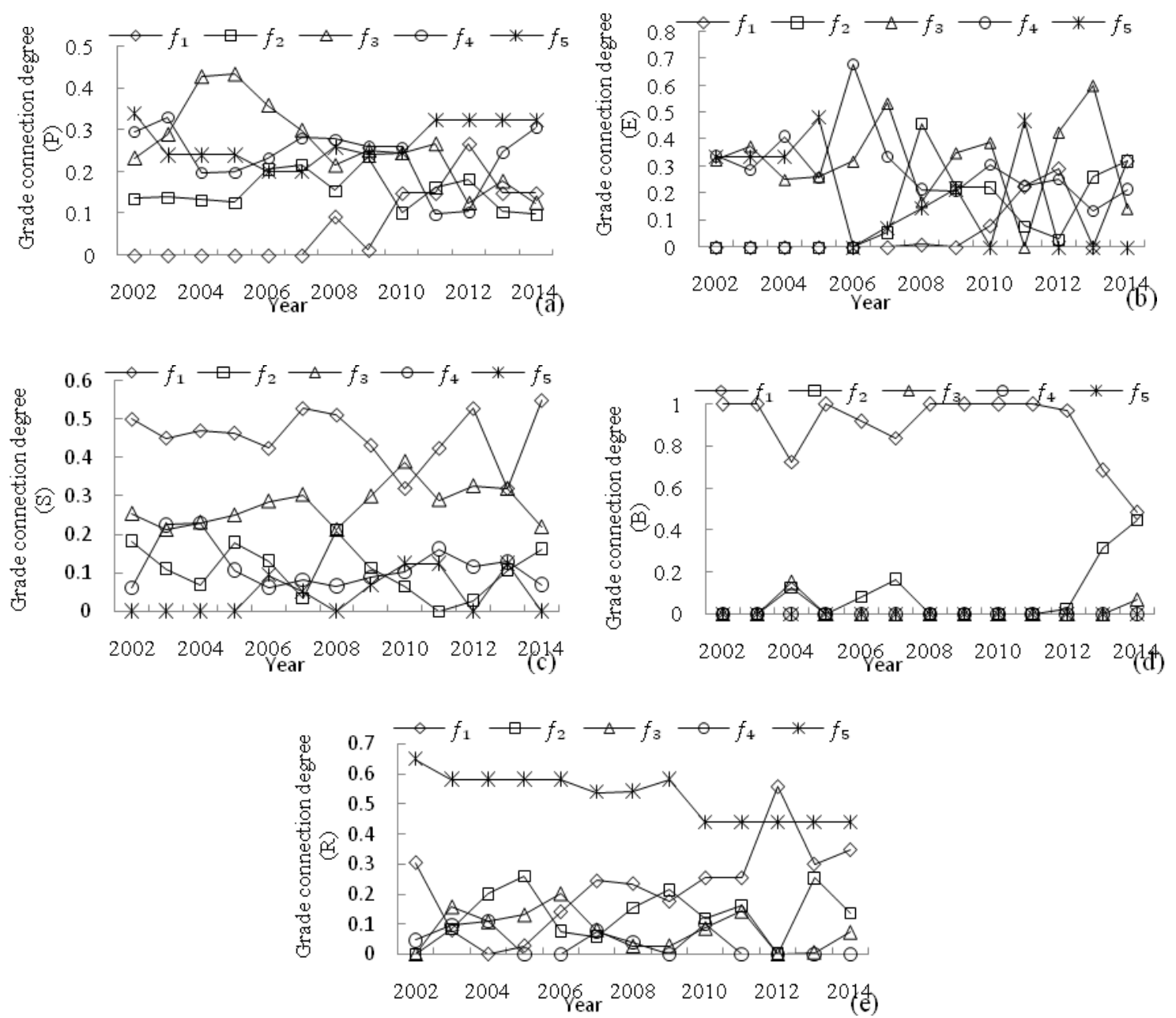

Fig. 3 Weighted grade of evaluation criteria(PESBR)

\section{Conclusions and Discussion}

\section{Conclusions}

(1) One of the important and difficult points of the study on the safety evaluation of water resources is how to construct the evaluation index system and classification standard. This paper designs a PESBR conceptual model based on the concept of PSR, the project in karst area water shortage index into the evaluation system, combined with the status quo and the national water resources planning and utilization safety related research at home and abroad, to determine the grading standards of each index, make up the index system without considering the defects of 
engineering water shortage situation, provide a new index system construct the basis for scientific evaluation of water resources security in karst area.

(2) Based on the SPA-MC coupling model on dynamic water resources of Guiyang city safety evaluation showed that the 2002-2014 in Guiyang city water resources safety general safe and safe level, the evaluation results are consistent with the actual, the next 2015-2050 years level of water resources security in Guiyang city will gradually shift from relatively safe to the security level. PESBR conceptual model analysis showed that the main driving factors of Guiyang City, to solve the problem of engineering water shortage, not only need to increase the construction of water conservancy facilities, enhance the effectiveness of storage water engineering, we should control the city population density, promote the conservation of water, improve the recycling rate of water resources.

(3) SPA-MC coupling evaluation model of comprehensive the state of water resources security and the future trend of uncertain information, in accordance with the evaluation object of Markov process, the evaluation result objective and easy method for comprehensive system dynamics evaluation has a certain reference value.

\section{Discussion}

For the research of karst and non-karst water resources security evaluation has become increasingly mature, on the basis of evaluation of karst engineering water shortage in dynamic water quality safety of Guiyang City, highlighting the constraints of engineering water shortage on the social and economic development in karst area, but because the data is limited, not to study the features of water resources security in the county the city in Guiyang city. In addition, the response mechanism and effect of the change of water resources in karst area under the global change environment need to be discussed.

\section{Acknowledgement}

The authors gratefully acknowledge the continued and valuable input by the Foundation of National Natural Science of China (41261038) and Major science and technology projects in Guizhou Province (No.6015[2012]).Our deepest gratitude also goes to the anonymous reviewers for their hard work and careful review.

\section{References}

[1] Yang Mingde, Tang Ming, Liang Hong.1998.Hydrology and geomorphology system of Karst River Basin[M].Beijing: Geological Publishing House.[in Chinese]

[2] Sun Ping, Xiao Feipeng, Li Zhijian.2012. Identification of drought disasters and analysis of the causes of severe drought in large rocky mountain area of Guangxi province[J]. China Rural Water and Hydropower, (1):91-94. [in Chinese]

[3] Li Jingwen, Yang Xuyou, Li Qingwen.2014. Comprehensive Studies on Anisotropy of Karst Aquifer Medium[J]. Hubei Agricultural Sciences, 53(8): 1737-1841. [in Chinese]

[4] Proclamation of the Minister-class Conference on the 2nd World Water of Man of the United Nations. The Water Security in the 21st Century[R].Proclamation of the Minister-class conference in Hague, 2000. 
[5] David Grey, Claudia W Sadoff. Sink or swim ? Water security for growth and development[J]. Water Policy, 2007, 9: 545-571.

[6] Xia Jun, Zhu Yizhong. 2002. The measurement of water resources security: A study and challenge on water resources carrying capacity[J]. Journal of natural resources, 17(3) :262-269. [in Chinese]

[7] Su Yin, Guan Dongjie, Su Weici. 2015. The assessment of water security in karst region by SPA model: A case study of Guizhou province [J].carsologica sinica , 34(6):560-569. [in Chinese]

[8] Cao Qi, Chen Xingqi, Shi Mangjiang. 2012. [J]. Evaluation of Water Resources Security in the Urban Area and Regulating Methods Based on DPSIR: A Case of Zhangye City Resources Science, 34(8):1591-1599. [in Chinese]

[9] Zhang Fentai, Wang Lachun, Su Weici.2015. The safety evaluation of Water resources Based on DPSIRM conceptual framework and Grey-Set pair model in karst region[J]. China Environmental Science,35(11): 3511-3520. [in Chinese]

[10] Wang Pengquan, Wang Sanchao, Zhang Yongming, et al.2014. Water security analysis of Shiyang river based on WEAP model[J]. China Rural Water and Hydropower,(9):92-99. [in Chinese]

[11] Jin Juliang, Wu Kaiya, Wei Yiming. 2008. Connection number based assessment model for watershed water security [J].SHUILI XUEBAO, 39(4):401-409. [in Chinese]

[12] Wu Kaiya, Jin Juliang. 2011. Projection Pursuit Model For Evaluation Of Region Water Resource Security Based On Changeable Weight And Information [J]. Resources and Environment in the Yangtze Basin, 20(9):1085-1090. [in Chinese]

[13] Dai Wen. 2010. Simulation of the water resources safety on system dynamic--a case study of Guizhou Province[J].Water science and Engineering Technology,(4): 4-8. [in Chinese]

[14] Wang Hongwei, Zhang Xin, Qiu Junnan. 2011. Application of fuzzy set pair analysis method in safety evaluation of water resources[J]. Journal of Northwest A F University (Nat. Sci. Ed.) ,39(10):209-214. [in Chinese]

[15] Chang Mingqi, Liu Jun-ping, Ma Wei.2011. Water resources security assessment based on support vector machine[J]. JOURNAL OF NATURAL DISASTERS, 20 (6):167-171. [in Chinese]

Gao Yuanyuan, Wang Hongrui, Xu Xinyi, et al.2012. Assessment of water resources security-case of quanzhou city in fujian province[J]. Journal of Natural Resources, 27,(2):204 -214 . [in Chinese]

[16] Zhang Fengtai1, Wang Lachun, Su Weici, et al. 2012. Evaluation on the safety of karst dualistic water resources by coupling model of entropy weight set pair[J]. Journal of Hydroelectric Engineering, 31(6):70-76. [in Chinese]

[17 Duan Qicai, Huang Jie, WANG Jie. 2012. Analysis of characteristics of water cycle and water safety in Yunnan Province [J]. Yangtze River,43(13):7-20.

[18] Zou Sheng zhang, Zhu Ming qiu, Tang Jiansheng, et al.2006. Water Resources Security in Karst Area of Southwest China: Problems and Counter measures[J]. ACTA GEOLOGICA SINICA, 80(10): 1637-1642. [in Chinese] 
[19] Zhao Keqin.1995. disposal and description of uncertainties based on the set pair analysis [J]. Information and control, 24 (3): 162-165. [in Chinese]

[20] Qin Peng, Sun Guozheng, Qin Zhihai, et al.2016.Evaluation Model of Water Environment Security Based on Multi Element Connection Number[J]. Journal of Mathematics in Practice and Theory ,46(2):165-171.

[21] Shi Chaoyan .2014. Improvement and application of Grey Markov chain[D]. Lanzhou University, Lanzhou.

[22] Zou Bo, An Heping. 2012.Research on Problem of Water Resources Security in Guizhou and Its Strategic Solutions[J]. Research of Agricultural Modernization, 33(5):529-534. [in Chinese]

[23] Zhang Junyi, Wang Lachun, Su Weici, et al. 2014. Status and Prospect of hydrological effects of human activities in Karst Area[J]. Geography Progress, 33(8):1125-1135. [in Chinese]

[24] Lu Yaoru, Zhang Feng e, Liu Changli, et al. 2006. Karst Water Resources in Typical Areas of China and Their Eco-hydrological Characteristics [J]. Acta Geoscientica Sinica, 27(5):393-402. [in Chinese]

[25] Yang Yu. 2006. Evaluation of weighting method in multi index comprehensive evaluation [J]. statistics and decision , (7):17-19. [in Chinese]

[26] Chang Mingqi, Liu Junping , Huang Qiang. 2008. Multi Objective Evaluation And Early Warning Of Water Resources Security Vague Set[J]. Journal of Hydroelectric Engineering, 27(3):81-87. [in Chinese]

[27] Wang Wenshen, Li Yueqing, Jin Juliang, et al. 2010. Water collection and analysis area[M]. Science Press, Beijing.[in Chinese]

[28] hang Yitao, Wu Shihui, Liu Xiaodong, et al. 2016. Dynamic evaluation of aviation maintenance safety based on set pair analysis and Markov chain[J].China Safety Science Journal, 26(1):122-128. [in Chinese]

[29] Kang Yong. 2013. Study on the risk of urban gas buried pipeline system [D]. Northeastern University, Shenyang. [in Chinese] 